\title{
Usefulness of chorionic villus sampling for prenatal diagnosis of thalassaemia: a clinical study in eastern India
}

\author{
Sujoy Dasgupta ${ }^{1}$, Kalyansree Chaudhury ${ }^{2}$, Kanchan Mukherjee ${ }^{3 *}$
}

\begin{abstract}
${ }^{1}$ Department of Gynaecological Oncology, Chittaranjan National Cancer Institute, Kolkata, West Bengal, India
${ }^{2}$ Department of Obstetrics \& Gynaecology, Burdwan Medical College, Burdwan, West Bengal, India

${ }^{3}$ Department of Obstetric Ultrasound, Remedy Medical Services, Kolkata, West Bengal, India
\end{abstract}

Received: 11 April 2015

Accepted: 09 May 2015

\author{
*Correspondence: \\ Dr. Kanchan Mukherjee, \\ E-mail: mukherjee.kanchan@gmail.com
}

Copyright: ( $)$ the author(s), publisher and licensee Medip Academy. This is an open-access article distributed under the terms of the Creative Commons Attribution Non-Commercial License, which permits unrestricted non-commercial use, distribution, and reproduction in any medium, provided the original work is properly cited.

\section{ABSTRACT}

Background: Aim: To review the usefulness of chorionic villus sampling for prenatal diagnosis of thalassaemia with focus on risk of miscarriage and stillbirth in Indian women and thus provide local data for counseling the prospective parents in similar situation.

Methods: This retrospective study reviewed the pregnancy outcome of 362 patients with thalassaemia who underwent transabdominal chorionic villus sampling between 10-13 weeks of gestation for prenatal diagnosis. Aspiration of chorionic villus tissue was done in $2 \mathrm{ml}$ normal saline under ultrasound guidance.

Results: The miscarriage (pregnancy loss before 24 completed weeks) rate in our study was $2.02 \%$. The stillbirth (pregnancy loss at or after 24 completed weeks) rate was 27 per 1000 total births. There was no incident of any limb deficiency in our study. In all cases adequate chorionic villus tissue was obtained for analysis.

Conclusions: Thalassaemia is a prevalent condition in Eastern India. Chorionic villus sampling is an effective and safe method for early diagnosis of fetal thalassaemia that helps to prevent birth of thalassaemic babies.

Keywords: Prenatal diagnosis, Chorionic villus sampling, Thalassaemia, miscarriage, Stillbirth

\section{INTRODUCTION}

Thalassaemia is one of the commonest monogenic disorders globally. It has been estimated that in excess of 300000 children are born each year with a severe inherited disorder of hemoglobin and that approximately $80 \%$ of these births occur in low- or middle-income countries. ${ }^{1}$

Thalassaemia in children, beside physical and emotional suffering, puts a major strain on national resources. The birth incidence calculated for homozygous thalassemics would be 11316 per year in India which are added each year to the existing load of homozygous thalassemics. ${ }^{2}$ Majority of these children become transfusion-dependent and have reduced life expectancy. Till date, the most cost-effective way of prevention of the birth of thalassaemia-affected babies is prenatal diagnosis (PND).

Chorionic Villus Sampling (CVS) is one of such prenatal diagnostic method, in which few villi from the chorion frondosum are collected by trans-cervical (TC-CVS) or trans-abdominal (TA-CVS) route. CVS has the advantage of early termination of pregnancy in a relatively safer way in case the results are abnormal. Again, if the CVS result is normal, it is very much reassuring for the couple.

Many studies showing the effectiveness of CVS have been done in other countries. ${ }^{3-7}$ We have not come across a study of notable size on CVS in Eastern India in the literature. 
The aim of our study is to assess the effectiveness and the risk of commonly mentioned complications of CVS, particularly the miscarriage and stillbirth in our population and thus provide the local data for counseling the prospective parents.

\section{METHODS}

In this retrospective study we reviewed the outcome of 362 mothers who underwent chorionic villus sampling for prenatal diagnosis at a private diagnostic clinic in Kolkata between June 2011 and December 2014.

All patients were referred to the clinic for prenatal diagnosis by chorionic villus sampling. Only patients with valid indication for CVS, with singleton pregnancy and no history of bleeding per vagina were enrolled in the study. All gave informed consent after counseling. They were advised to empty their bladder before the procedure to avoid inadvertent bladder injury. A thorough ultrasonic assessment was done on each patient to confirm singleton pregnancy with live fetus at 10-13 weeks of gestation. Nuchal translucency was noted as well as any other obvious fetal anomalies. Particular attention was paid on location of placenta and its accessibility. All procedures were done transabodiminally under direct ultrasonic guidance with $5 \mathrm{ml}$ of $2 \%$ xylocaine infiltration for local anesthesia. 18G Spinal needle was introduced under direct ultrasonic vision after ensuring local anesthesia. The stellate was removed keeping the tip of the needle into the thick part of the chorionic plate. Aspiration was done in $2 \mathrm{ml}$ normal saline through a $10 \mathrm{ml}$ disposable syringe. The collected samples were cleaned in normal saline to discard visible blood clots. All samples were sent in normal saline to the respective labs on the same day. Our study is unique in a way that no transport media was used to carry samples. The primary purpose of this was cost reduction as most of our patients came from lower socioeconomic background. However there was not a single case of sample failure in this series. Patients were discharged within half an hour after the procedure on broad spectrum antibiotics for five days.

Maternal details and ultrasound findings were recorded at the time of ultrasound scan in the clinic. Pregnancy outcome data were recorded at the database as it was subsequently available from the patients during the follow-up or by direct questionnaire.

Comparison of the outcome data between our study and background rate as found in other studies was done by Chi squared test.

All procedures were done by one of the authors (KM) trained in fetal medicine.

The miscarriage is defined here as pregnancy loss before 24 completed weeks of gestation. Stillbirth is defined as a birth of a newborn at or after $24^{\text {th }}$ completed weeks of gestation who does not show any sign of life after delivery. Limb reduction defect or limb deficiency, a selfexplanatory term, refers to certain congenital defects of the extremities that are found in the newborn following chorionic villus sampling in early pregnancy.

\section{RESULTS}

In this study a total of 450 CVS were performed over three and a half years in the clinic. Of these, ten cases were excluded, as the indications were different. Four of them were for Spinal Muscular Atrophy (SMA) and three each for haemophilia and sickle cell anaemia. Thus in remaining 440 cases, CVS were performed to find out the thalassaemia status of the fetus. Out of them 78 women were lost in follow up. So, finally the outcomes of CVS in 362 women were available for analysis (Table 1). All the mothers, referred to the clinic with valid indications for CVS, opted for CVS after counseling. Hence there was no control arm.

\section{Table 1: Total number of CVS performed.}

\begin{tabular}{|ll|}
\hline Total number of CVS performed & \\
\hline Total number of CVS performed & 450 \\
\hline Indications other than thalassaemia & 10 \\
\hline Indications thalassaemia & 440 \\
\hline Lost in follow up & 78 \\
\hline Final number of women analysed in the study & 362 \\
\hline
\end{tabular}

The demographic variables of the women participated in this study are shown in Table 2.

Table 2: Demographic variables of the women participating in the study.

\begin{tabular}{|lll|}
\hline Characteristics & N=362 & \\
\hline Age (years) & Mean \pm SD & Range \\
\hline Parity & $25.2 \pm 1.7$ & $21-35$ \\
\hline Gestational age (weeks) & $1.3 \pm 0.7$ & $0-4$ \\
\hline
\end{tabular}

All but two cases required single puncture. In majority of the cases the placenta was located posteriorly or laterally. In all 362 cases chorionic villus was collected successfully. All the women having Rhesus negative blood group, received anti-D globulin (Table 3).

Table 3: Procedural details of the CVS.

\begin{tabular}{|lll|}
\hline Characteristics & & Number $(\mathrm{N}=362)$ \\
\hline \multirow{2}{*}{ Placenta } & Single & $360(99.45 \%)$ \\
\cline { 2 - 3 } & Double & $2(0.55 \%)$ \\
\hline Blood group & Anterior & $125(34.53 \%)$ \\
\cline { 2 - 3 } & $\begin{array}{l}\text { Posterior / } \\
\text { Lateral }\end{array}$ & $237(65.47 \%)$ \\
\hline & Positive & $350(96.69 \%)$ \\
\hline
\end{tabular}


It is interesting to note that in majority (315 out of 362) of the cases the couples came to know about their thalassaemia status after having one baby affected with thalassaemia major. In the remaining 47 cases the couples did not have any affected children (Table 4 and Figure 1). This proves the lack of awareness in antenatal screening for the commonest inborn haemoglobinopathy in this part of the world.

Table 4: Indications of CVS with the objective of detection of thalassaemia.

\begin{tabular}{|ll|}
\hline Indications of CVS & $\begin{array}{l}\text { Number } \\
(\mathrm{N}=362)\end{array}$ \\
\hline $\begin{array}{l}\text { Previous baby } \\
\text { thalasaemia major }\end{array}$ & $315(87.02 \%)$ \\
\hline $\begin{array}{l}\text { No previous baby } \\
\text { affected (both the } \\
\text { parents carrier) }\end{array}$ & $47(12.98 \%)$ \\
\hline
\end{tabular}

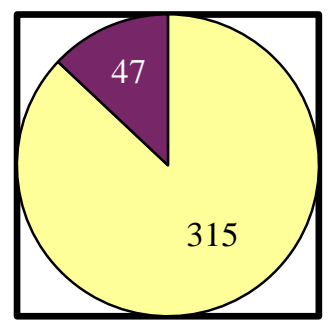

$\square$ Previous baby thalassaemia major

$\square$ No previous baby affected (both parents carrier)

Figure 1: Indications of CVS.

Out of the 362 women who could be followed up, 65 terminated the pregnancy as their fetuses had been found to be affected with thalassaemia major. However, in majority of the cases, the fetus was found to be unaffected or carrier as expected (Table 5 and Figure 2).

Table 5: Results of CVS.

\begin{tabular}{|ll|}
\hline $\begin{array}{l}\text { Fetal haemoglobin } \\
\text { status }\end{array}$ & Number \\
\hline Normal & $211(58.28 \%)$ \\
\hline Thalassaemia trait & $86(23.76 \%)$ \\
\hline Thalassaemia major & $65(17.96 \%)$ \\
\hline
\end{tabular}

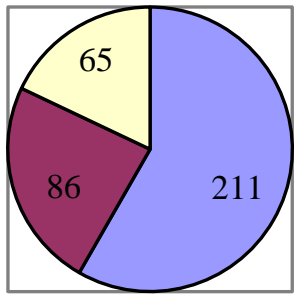

$$
\begin{aligned}
& \square \text { Normal } \\
& \square \text { Thalasaemia trait } \\
& \square \text { Thalassaemia major }
\end{aligned}
$$

Figure 2: Results of CVS.
Majority of the women undergoing CVS had uneventful pregnancy. We encountered six cases of spontaneous miscarriage occurring within 24 weeks of gestation. There were eight cases of still birth. However, there was

\begin{tabular}{|c|c|c|c|c|}
\hline Complications & $\begin{array}{l}\text { Our } \\
\text { study }\end{array}$ & $\begin{array}{l}\text { Background } \\
\text { rate }\end{array}$ & $\begin{array}{l}\mathbf{P} \\
\text { value }\end{array}$ & Remarks \\
\hline Miscarriage & $\begin{array}{l}6 / 297 \\
(2.02 \%)\end{array}$ & $1.2 \%$ & $>0.1$ & $\begin{array}{l}\text { Nothing } \\
\text { significant } \\
\text { (NS) }\end{array}$ \\
\hline Still birth & $\begin{array}{l}8 / 291 \\
(2.75 \%)\end{array}$ & $3.0 \%$ & $>0.1$ & N.S \\
\hline
\end{tabular}
no case of limb deficiency (Table 6 and Figure 3).

Table 6: Complications related to CVS.

$2.00 \%$
$2.00 \%$
$1.50 \%$
$0.50 \%$
$0.00 \%$

Figure 3: Complications related to CVS.

Out of the 362 women followed up, 283 have delivered healthy babies (Table 7).

Table 7: Outcome of pregnancy.

\begin{tabular}{|ll|}
\hline Outcomes & Number $(\mathrm{N}=362)$ \\
\hline Termination due to affected baby & $65(17.96 \%)$ \\
\hline Miscarriage & $6(2.02 \%)$ \\
\hline Still birth & $8(2.69 \%)$ \\
\hline Delivery of live baby & $283(95.29 \%)$ \\
\hline
\end{tabular}

\section{DISCUSSION}

Thalassaemia is a common genetic problem in Indian population. Apart from the suffering, both emotionally and physically, it puts a major strain on the health resources. CVS, an effective method of making an early diagnosis of fetal chromosomal and genetic disorders, helps in decision making for the couples. We have not found any notable study in the literature on the risk of CVS in Eastern India. The results of this study will be useful for counseling the prospective parents in our population who intend to undertake CVS.

All the mothers had valid indication for prenatal diagnosis by chorionic villus sampling. They were referred to the clinic for prenatal diagnosis by CVS. All of them opted for chorionic villus sampling. Hence this 
study had no control arm and we could not compare miscarriage rates for the matched population.

In several studies the sampling success rate of CVS varied between $97-100 \%$, which increased with advanced gestation. ${ }^{5,8,9}$ In one study the procedure failed to obtain an adequate sample in $0.3 \%$ cases. $^{6}$ In our study, the sampling success rate was $100 \%$ as in all cases chorionic tissue was collected.

Number of needle insertions and its effects were analyzed in some studies. One study reported that in $86.9 \%$ cases single needle insertion was successful. ${ }^{10}$ No difference in pregnancy loss rate followed one or two catheter or needle insertions, but the need for three insertions was associated with a significantly increased loss rate. ${ }^{11}$ Similarly, in our study, out of 362 women, in 360 cases a single puncture was sufficient but in two women double puncture was required without any significant adverse consequence in their pregnancy.

Regarding the position of the placenta, a Pakistani study showed that placenta at any position (anterior or posterior) can be approached without significant trauma to the mother and fetus. ${ }^{7}$ Similarly in our case, samples were collected in all cases irrespective of the position of the placenta.

Inconclusive results may be a problem after CVS. One study reported that $3.4 \%$ of CVS had inconclusive result. ${ }^{5}$ However, in our study, none of the 362 women followed up had inconclusive results.

A Chinese study reported that $12 \%$ of the fetuses had thalasaemia major after CVS. ${ }^{12}$ Conversely, an Iranian study also demonstrated $18 \%$ of fetuses were diagnosed to have beta thalassaemia major. ${ }^{10}$ Similarly, in our study, $18 \%$ of the fetuses were diagnosed to have thalassaemia major, consistent with the other Asian studies.

Early fetal loss (miscarriage) and late fetal loss (stillbirth) are major concerns following CVS as in any invasive prenatal diagnostic procedure. In this study, the rate of miscarriage and stillbirth were 6/297 (2.02\%) and 8/291 $(2.75 \%)$. One large cohort study reported a miscarriage rate of $1.9 \%$ following CVS which is similar to that in our study. ${ }^{13}$ As there is no control in this study, we have compared the miscarriage rate and stillbirth rate with the background rate. The background miscarriage rate and stillbirth rate in general obstetric population after demonstration of a live fetus at 11-13 weeks gestation were noted to be $1.2 \%$ and $0.43 \%$ respectively in one large study. ${ }^{14}$ No significant difference was found in miscarriage rate after demonstration of a live fetus at 1113 weeks of gestation between Caucasian women and South Asian women and also East Asian women. ${ }^{15}$ The difference between the miscarriage rate in our study and the background rate is $0.82 \%$ which is not statistically significant. Similar difference in miscarriage rate $(0.7 \%)$ has been observed in a very large study. ${ }^{14}$ Similar procedure-related fetal loss ranging from $0.3 \%$ to $0.8 \%$ were reported by several other studies ${ }^{5-7,16,17}$ though one study reported a fetal loss rate of $1.41 \% .^{18}$ The stillbirth rate in this study is $8 / 291$ ( 27 per 1000 total births). It is not significantly different from the stillbirth rate reported by these studies from India. ${ }^{19,20}$ Similarly, no significant difference in stillbirth rate is also noted by another large study. ${ }^{14}$

Apparently the procedural risk in CVS could be estimated by comparing outcome in pregnant women who had undergone CVS with those who did not have test. But actually in such an approach the risk of CVS would be overestimated because the contribution of the indication of CVS would be overlooked. The best way of estimating such risks would be a randomized study comparing test group undergoing CVS with control group without CVS. Unfortunately most of women would opt for CVS after proper counseling and such a study would be difficult.

The lower miscarriage rate after CVS could be explained by the theory that placenta is a spongy organ that will expand easily after the procedure allowing better healing than if the needle had been passed through the amnion which is even more stretched by the amniotic cxfluid. The data indicate that the fetal loss rate improved with experience of the operator. ${ }^{13}$ Limb reduction defect in infants following CVS is a major concern for both the clinicians and the couples. Although the cause is unknown, researchers have hypothesized that these deficiencies are caused by vascular disruption either during the formation of embryonic limbs or in alreadyformed fetal limbs. ${ }^{21}$ This association between limb reduction and CVS was first raised in a study reporting five babies with limb reduction defects were born to women undergoing transabdominal CVS between 56-66 days of gestation. ${ }^{22}$ Though World Health Organization (WHO) International Registry for Limb Defects after CVS found no difference in prevalence of limb defects after CVS compared with background population, ${ }^{23}$ current recommendation is not to perform CVS before 10 completed weeks of gestation. ${ }^{24}$ Gogate S, 2006 reported an experience of over 10000 cases of CVS, There was no case of limb reduction deformity following CVS in this study ${ }^{9}$ similar to another study result. ${ }^{5}$ Another Thai study, where CVS was done after 10 weeks of gestation, reported no incidence of limb reduction defect. ${ }^{17}$

\section{CONCLUSIONS}

Thalassaemia is a prevalent condition in the population we studied. Obstetricians have to play important role by generating awareness among the general population as well as screening of antenatal population for thalassaemia besides other routine antenatal investigations. CVS is an acceptable, reliable and safe method of early diagnosis of fetal thalassaemia that helps to prevent birth of the thalassaemia-affected babies with considerable reduction of socio-economic burdens. Also, normal saline as a transport medium is highly effective, cheap and readily available. 


\section{ACKNOWLEDGEMENTS}

We acknowledge the contribution of Dr. Shyamsundar Mandal of Chittaranjan National Cancer Institute, Kolkata for statistical analysis.

Funding: No funding sources

Conflict of interest: None declared

Ethical approval: The study was approved by the institutional ethics committee

\section{REFERENCES}

1. Weatherall DJ. The inherited disorders of hemoglobin are an emerging global health burden. Blood. 2010;115:4331-6.

2. Nishi Madan, Satendra Sharma, S. K. Sood, Roshan Colah, (Late) H. M. Bhatia. Frequency of $\beta$ thalassemia trait and other hemoglobinopathies in northern and western India. Indian $\mathbf{J}$ Hum Genet. 2010 Jan-Apr;16(1):16-25.

3. Tasleem S, Tasleem H, Siddiqui MA, Adil MM, Rashid Y. Prenatal diagnosis of beta-thalassaemia by chorionic villous sampling. J Pak Med Assoc. 2007 Nov;57(11):528-31.

4. Rhoads GG, Jackson LG, Schlesselman SE, de la Cruz FF, Desnick RJ, Golbus MS, et al. The safety and efficacy of chorionic villus sampling for early prenatal diagnosis of cytogenetic abnormalities. N Engl J Med. 1989;320:609-17.

5. Laksanavilai U, Piyamongkol W, Sirichotiyakul S, Tongprasert F, Leuwan S, Srisupundit K. Chorionic villous sampling: experience of 636 cases. J Med Assoc Thai. 2013 Apr;96(4):383-8.

6. Han J, Pan M, Zhen L, Yang X, Ou YM, Liao C, et al. Chorionic villus sampling for early prenatal diagnosis: experience at a mainland Chinese hospital. J Obstet Gynaecol. 2014 Jun;9:1-4.

7. Ahmed S. Transabdominal chorionic villus sampling (CVS) for prenatal diagnosis of genetic disorders. J Coll Physicians Surg Pak. 2006 Mar;16(3):204-7.

8. Choudry A, Masood S, Ahmed S. Feasibility and safety of transabdominal Chorionic Villus Sampling. J Ayub Med Coll Abbottabad. 2012 JanMar;24(1):38-43.

9. Gogate S. Methods of fetal tissue sampling and prenatal diagnosis. In: Pai HR, eds. Manual of Genetics and Fetal Medicine. Mumbai: Genetics and Fetal Medicine Committee FOGSI; 2006: 22.

10. Asnafi N, Akhavan Niaki H. Pregnancy outcome of chorionic villus sampling on 260 couples with betathalassemia trait in north of Iran. Acta Med Iran. 2010 May-Jun;48(3):168-71.

11. Williams J 3rd, Wang BB, Rubin CH, AikenHunting D. Chorionic villus sampling: experience with 3016 cases performed by a single operator. Obstet Gynecol. 1992 Dec;80(6):1023-9.

12. He S, Li D, Lai Y, Zhang Q, Que T, Tang Y, et al. Prenatal diagnosis of $\beta$-thalassemia in Guangxi Zhuang Autonomous Region, China. Arch Gynecol Obstet. 2014 Jan;289(1):61-5.

13. Tabor A, Vestergaard CHF, Liddegard $\varnothing$. Fetal loss rate after chorionic villus sampling and amniocentesis: an 11-year national registry study. Ultrasound Obstet Gynecol. 2009;34:19-24.

14. Akolekar R, Bower S, Flack N, Bilardo ACM, Nicolaides KH. Prediction of miscarriage \& stillbirth at 11-13 weeks and contribution of chorionic villus sampling. Prenat Diagn. 2011;31:38-45.

15. Khalil A, Rejende Z, Akolekar R, Syngelaki A, Nicolaides KH. Maternal racial origin and adverse pregnancy outcome: a cohort study. Ultrasound Obstet Gynecol. 2013;41:278-85.

16. Lau KT, Leung YT, Fung YT, Chan LW, Sahota DS, Leung NT. Outcome of 1355 consecutive transabdominal chorionic villus samplings in 1351 patients. Chin Med J (Engl). 2005;118(20):1675-81.

17. Sirichotiyakul S, Piyamongkol W, Tongprasert F, Srisupandit K, Luewan S. Transabdominal chorionic villus sampling: experience at Maharaj Nakorn Chiang Mai Hospital. J Med Assoc Thai. 2008 Jun;91(6):813-7.

18. Akhlaghpoor S. Chorionic villus sampling for betathalassemia: the first report of experience in Iran. Prenat Diagn. 2006 Dec;26(12):1131-6.

19. Rajaratnam JK, Marcus AR, Flaxman AD, Wang H, Levin-Rector A, Dwyer L, et al. Neonatal, postneonatal, childhood and under-5 mortality for 187 countries, 1970 - 2010: a systematic analysis of progress towards Millenium Development Goal 4. Lancet. 2010;375(9730):1988-2008.

20. Bhati DK. Stillbirths: a high magnitude public health issue in India. South East Asia J Public Health. 2013;3(1):3-9.

21. Olney RS, Moore CA, Khoury MJ, David Erickson J, Edmonds LD, Botto LD. Chorionic villus sampling and amniocentesis: recommendations for prenatal counselling. MMWR. 1995;44(RR-9):1-12.

22. Firth HV, Boyd PA, Chamberlain P, MacKenzie IZ, Lindenbaum RH, Huson SM. Severe limb abnormalities after chorionic villus sampling at 5666 days' gestation. Lancet. 1991;337:762-3.

23. Medical Research Council European Trial of Chorion Villus Sampling. MRC working party on the evaluation of chorionic villus sampling [comment]. Lancet. 1991;337(8756):1491-9.

24. RCOG. Green-top Guideline No.8. In: RCOG, eds. Amniocentesis and Chorionic Villus Sampling. UK: RCOG; June 2010: 3.

DOI: $10.18203 / 2320-1770 . i j r \operatorname{cog} 20150093$

Cite this article as: Dasgupta S, Chaudhury K,

Mukherjee K. Usefulness of chorionic villus sampling for prenatal diagnosis of thalassaemia: a clinical study in eastern India. Int $\mathbf{J}$ Reprod Contracept Obstet Gynecol 2015;4:790-4. 